\title{
Different evolutionary pathways underlie the morphology of wrist bones in hominoids
}

Tracy L Kivell ${ }^{1,2^{*}}$, Anna P Barros ${ }^{3}$ and Jeroen B Smaers ${ }^{4,3,5}$

\begin{abstract}
Background: The hominoid wrist has been a focus of numerous morphological analyses that aim to better understand long-standing questions about the evolution of human and hominoid hand use. However, these same analyses also suggest various scenarios of complex and mosaic patterns of morphological evolution within the wrist and potentially multiple instances of homoplasy that would benefit from require formal analysis within a phylogenetic context. We identify morphological features that principally characterize primate - and, in particular, hominoid (apes, including humans) - wrist evolution and reveal the rate, process and evolutionary timing of patterns of morphological change on individual branches of the primate tree of life. Linear morphological variables of five wrist bones - the scaphoid, lunate, triquetrum, capitate and hamate - are analyzed in a diverse sample of extant hominoids (12 species, 332 specimens), Old World (8 species, 43 specimens) and New World (4 species, 26 specimens) monkeys, fossil Miocene apes (8 species, 20 specimens) and Plio-Pleistocene hominins (8 species, 18 specimens).

Result: Results reveal a combination of parallel and synapomorphic morphology within haplorrhines, and especially within hominoids, across individual wrist bones. Similar morphology of some wrist bones reflects locomotor behaviour shared between clades (scaphoid, triquetrum and capitate) while others (lunate and hamate) indicate clade-specific synapomorphic morphology. Overall, hominoids show increased variation in wrist bone morphology compared with other primate clades, supporting previous analyses, and demonstrate several occurrences of parallel evolution, particularly between orangutans and hylobatids, and among hominines (extant African apes, humans and fossil hominins).

Conclusions: Our analyses indicate that different evolutionary processes can underlie the evolution of a single anatomical unit (the wrist) to produce diversity in functional and morphological adaptations across individual wrist bones. These results exemplify a degree of evolutionary and functional independence across different wrist bones, the potential evolvability of skeletal morphology, and help to contextualize the postcranial mosaicism observed in the hominin fossil record.
\end{abstract}

Keywords: Carpal, Functional morphology, Locomotion, Phylogeny, Variable rates estimation

\section{Background}

A detailed understanding of the evolutionary patterns and processes that underlie skeletal morphology are crucial to explaining present-day diversity and interpreting the fossil record. The process of morphological evolution has long been viewed as one of a clear form-function relationship involving gradual adaptation to specific biota

\footnotetext{
* Correspondence: t.l.kivell@kent.ac.uk

${ }^{1}$ School of Anthropology and Conservation, University of Kent,

Canterbury, UK

${ }^{2}$ Department of Human Evolution, Max Planck Institute for Evolutionary

Anthropology, Leipzig, Germany

Full list of author information is available at the end of the article
}

[1]. However, fossil evidence of mosaic and/or convergent evolution within or across different morphological modules [2-7] demonstrates that the evolutionary process is more complex. Comparative morphological analyses within a phylogenetic framework help to unravel the complex patterns of skeletal morphological evolution [8-10] and are essential for 1) assessing evolutionary trends $[10,11], 2)$ inferring changes in rates of evolution [12], and 3 ) ascertaining whether observed similarities result from common descent or are acquired independently $[8,13]$.

Order Primates is an ideal clade to further our understanding of skeletal morphological evolution within a phylogenetic context. Primates are characterised by a

\section{() Biomed Central}


diverse range of locomotor adaptations, including behaviours not seen in other extant mammals, such as vertical clinging and leaping, ricochetal brachiation, and striding, straight-leg bipedalism. Within primates, the functional morphology of wrist and hand is of particular interest because an increased reliance on the hindlimbs to power locomotion [14] promotes a decoupling of hind- and forelimb functions, leaving the forelimb free to be used more for movements of guidance, grasping and manipulation [15].

The hominoid wrist has received special attention because of its implications for human evolutionary history, including the mode of locomotion from which bipedalism emerged [16-20], the degree of arboreality in early hominins [4,21-23], and the evolution of human dexterity [22,24-27]. In particular, features shared between the human and African ape wrist have been interpreted as evidence that human bipedalism evolved from a knucklewalking ancestor $[8,17,28,29]$, while others consider these features to have evolved in parallel in African apes and their presence in humans to be largely the result of a close phylogenetic relationship to $\operatorname{Pan}[18,20,30]$. The interpretation of Ardipithecus ramidus as distinctly unlike extant hominoids prompted the researchers to propose that all knuckle-walking, climbing and suspensory features, including those of the wrist and hand, shared by extant hominoids evolved in parallel [31]. Furthermore, fossil hominoids and hominins demonstrate a high level of postcranial mosaicism - the concept that certain morphological features may undergo evolutionary change at different rates than other morphological features in a lineage [32] [e.g. Sivapithecus [33,34]; Ar. ramidus [31], Australopithecus sediba [3,35,36], Au. afarensis [4]] complicating the interpretation of the evolutionary pathways of particular morphologies.

Part of the debate over the processes that characterize the morphological evolution of the hominoid wrist, and skeletal morphology in general, may result from the methods that have been used to infer its evolutionary history. Although homoplasies can only be identified within a phylogenetic context, many of the hypotheses of parallel evolution within hominoids are largely post hoc interpretations without a formal analytical consideration of phylogeny. Studies utilizing morphologically-based phylogenetic inferences to quantify rates of evolution [8,37-42] assume a clear association between morphological and evolutionary diversity that is highly problematic in cases of mosaic evolution. Previous research on primate hard and soft tissue anatomy, for example, has shown varying degrees of congruence between the morphology-based phenetic trees and molecular-based phylogenies $[8,43,44]$.

To understand the patterns of phenotypic change that occur in relation to genotypic diversification, phenotypic data can be mapped onto an independently-estimated, molecular-based phylogenetic tree $[12,45]$. This approach highlights processes of phenotypic change occurring across individual branches of a phylogeny and therefore has the potential to identify processes such as convergence and mosaic evolution within the skeleton. Here, we apply this phylogenetically-integrated approach to quantify evolutionary changes in primate wrist morphology (38 linear variables on five wrist bones, Figure 1 and Additional files 1 and 2) over 47 million years of evolution and across 24 extant primate species (401 specimens; Table 1) and 16 fossil primate taxa (38 specimens; Table 2) of varying locomotor behaviours. This approach moves away from direct species comparisons by (1) utilizing independently-estimated (molecular) phylogenies to identify which morphological signals dominate the evolution of an anatomical module (i.c., the wrist) and (2) inferring the timing and rate of evolutionary changes along individual lineages. By quantifying evolutionary changes along individual branches of the tree of life, our approach allows robust inferences of instances of independent evolution and provides a useful framework to help interpret fossil morphology, especially in cases where taxonomy is uncertain. Here, we explore the evolutionary pathways that underlie extant and fossil hominoid wrist morphology within a phylogenetic context to test previously proposed hypotheses of independent evolution and to explore the potential for mosaic evolution within this key morphological area.

\section{Results and discussion}

We investigated the evolution of wrist bone morphology across a sample of extant and fossil haplorrhines using a phylogenetically-integrated approach that quantifies evolutionary changes along individual branches of an independently-derived phylogeny. Although the eight or nine carpal bones that comprise the primate wrist can be described as functioning as an anatomical module linking the forearm to the hand, our results demonstrate

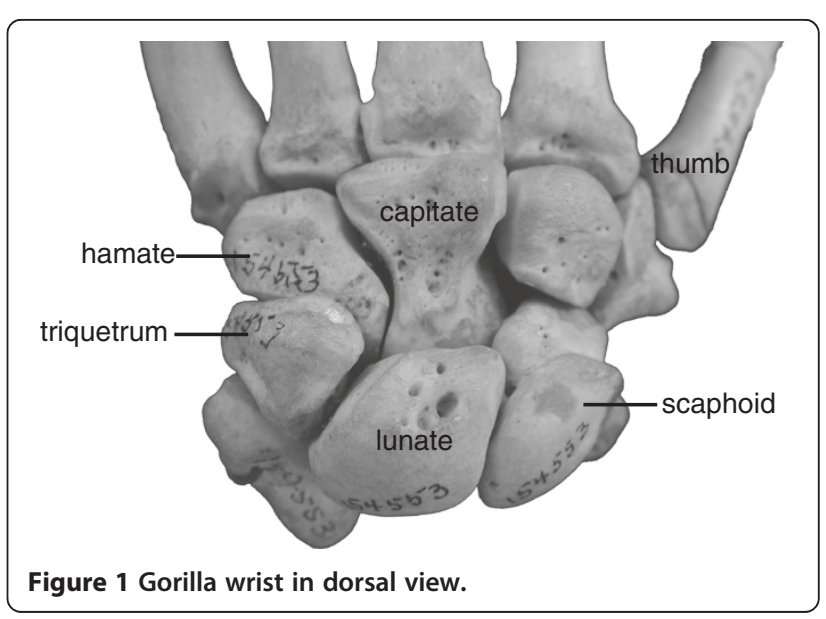


Table 1 Extant primate sample used in this study

\begin{tabular}{|c|c|c|c|c|}
\hline Group & Taxon & $N$ & $\begin{array}{l}\text { Body mass }(\mathrm{kg}) \text { range } \\
{\mathrm{F}-\mathrm{M}^{\mathrm{a}}}\end{array}$ & Locomotor behaviours \\
\hline \multirow[t]{3}{*}{ NWM } & Lagothrix lagotricha & 7 & $7.0-9.3$ & arboreal quadruped, with climbing and orthograde clambering ${ }^{b}$ \\
\hline & Ateles sp. & 4 & 7.3-8.9 & torso-orthograde suspensory; semi-brachiator ${ }^{c}$ \\
\hline & Alouatta sp. & 13 & $5.4-7.2$ & arboreal quadruped, with climbing and orthograde clambering \\
\hline \multirow[t]{12}{*}{ Hominoids } & Pongo pygmaeus & 25 & $35.8-78.5$ & torso-orthograde suspensory ${ }^{d}$ \\
\hline & Pongo abelii & 9 & $35.6-77.9$ & torso-orthograde suspensory \\
\hline & Pan troglodytes verus & 14 & $41.6-46.3$ & knuckle-walker (arboreal and terrestrial) and climbing ${ }^{\mathrm{e}}$ \\
\hline & $\begin{array}{l}\text { Pan troglodytes } \\
\text { troglodytes }\end{array}$ & 25 & $45.8-59.7$ & knuckle-walker (arboreal and terrestrial) and climbing \\
\hline & $\begin{array}{l}\text { Pan troglodytes } \\
\text { schweinfurthii }\end{array}$ & 6 & $33.7-42.7$ & knuckle-walker and climbing (proportion of arboreality varies from 33-68\%) \\
\hline & Pan paniscus & 19 & $33.2-45.0$ & $\begin{array}{l}\text { knuckle-walker (arboreal and terrestrial) and climbing, considered more arboreal } \\
\text { than P. troglodytes }\end{array}$ \\
\hline & Homo sapiens & 146 & $54.4-62.2$ & terrestrial biped \\
\hline & Gorilla gorilla gorilla & 40 & $71.5-170.4$ & terrestrial knuckle-walker (assumed to be less terrestrial than G.b.beringei) ${ }^{9}$ \\
\hline & Gorilla beringei graueri & 7 & $71.0-175.2$ & terrestrial knuckle-walker (assumed to be less terrestrial than G.b.beringei) \\
\hline & Gorilla beringei beringei & 9 & $97.5-162.5$ & terrestrial knuckle-walker (most terrestrial of all Gorilla, 93-98\% terrestrial) \\
\hline & $\begin{array}{l}\text { Symphalangus } \\
\text { syndactylus }\end{array}$ & 5 & 10.7-11.9 & brachiator $^{\text {h }}$ \\
\hline & Hylobates lar & 27 & $5.4-5.9$ & brachiator \\
\hline \multirow[t]{8}{*}{ OWM } & Presbytis sp. & 2 & $5.6-6.8$ & arboreal quadruped, capable of leaping and forelimb suspension ${ }^{i}$ \\
\hline & Macaca mulatta & 16 & $8.8-11.0$ & semi-terrestrial quadruped ${ }^{j}$ \\
\hline & Macaca fascicularis & 7 & 3.6-5.4 & arboreal quadruped $^{k}$ \\
\hline & Papio Anubis & 6 & $13.3-25.1$ & terrestrial quadruped' \\
\hline & Theropithecus gelada & 5 & $11.7-19.0$ & terrestrial quadruped \\
\hline & Chlorocebus aethiops & 4 & $3.0-5.5$ & semi-terrestrial quadruped \\
\hline & Erythrocebus patas & 3 & $6.5-12.4$ & terrestrial quadruped \\
\hline & Cercopithecus mitis & 12 & $3.9-5.9$ & arboreal quadruped \\
\hline
\end{tabular}

Although we recognize that most primate taxa engage in a wide range of locomotor and postural behaviours, our summary here is only a brief description of the most frequent locomotor behaviour and environment.

a Smith and Jungers (1997).

b Describes a variety of locomotor behaviors, including quadrupedalism, climbing, and orthograde clambering, in an arboreal context (Cant et al., 2001, 2003).

' Describes both torso-orthograde clambering and brachiation, which make up 50\% of arboreal locomotion (Cant et al., 2001, 2003).

d Describes both torso-orthograde clambering and brachiation which make up 35-60\% of arboreal locomotion (Cant, 1987; Thorpe and Crompton, 2006).

e Describes both terrestrial knuckle-walking - the primary mode of locomotion - in addition to various arboreal locomotor behaviours, including knuckle-walking,

vertical climbing, clambering and suspension (Hunt 1991; Doran, 1996).

${ }^{f}$ Doran $(1992,1993)$.

${ }^{g}$ Hunt (1992) and Doran (1996).

h Hunt (1991).

i Fleagle (1977).

j Describes OWM that engage in roughly equal time in both terrestrial and arboreal environments (Rose, 1979; Wells and Turnquist, 2001).

${ }^{k}$ Describes OWM that engage primarily in quadrupedalism in an arboreal environment (Cant, 1988; Gebo and Chapman, 1995).

' Describes Old World monkeys (OWM) that engage in >68\% terrestrial quadrupedal locomotion (Rose, 1977; Hunt, 1991; Fleagle, 1999).

that the morphology of individual wrist bones follows different evolutionary pathways, supporting the view that the wrist is better considered as an integrated, complex system of joints in which individual bones have a degree of functional and evolutionary independence [46-52]. The evolutionary morphological changes in some wrist bones are consistent with similarities in locomotor behaviour shared across taxa (scaphoid, triquetrum and capitate) while others (lunate and hamate) indicate taxon- or clade-specific synapomorphic patterns. Generally, within our sample, hominoids display more morphological variation, particularly in the hamate ( $\mathrm{PC1}: F=7.25, P<$ 0.001; PC2: $F=7.92, P<0.001$ ), triquetrum (PC1: $F=5.02$, $P<0.001 ; \mathrm{PC} 2: F=2.85, P=0.017$ ), lunate (PC1: $F=4.34$, $P<0.005$; PC2: $F=1.23, P=0.67$ ), and capitate (PC1: $F=$ 1.79, $P=0.16$; PC2: $F=11.64, P<0.001)$ than New World monkeys (NWM) and Old World monkeys (OWM), supporting previous analyses of the wrist [53-56]. The increased 
Table 2 Fossil hominoid sample used in this study

\begin{tabular}{|c|c|c|}
\hline Carpal & Taxon & Specimen \\
\hline \multirow[t]{7}{*}{ Scaphoid } & Proconsul africanus & KNM SO 999* \\
\hline & Proconsul heseloni & KNM RU 2036*, C14* \\
\hline & Oreopithecus bambolii & Basel 26* \\
\hline & Australopithecus sp. & StW 618 \\
\hline & Australopithecus sediba & MH2 UW 88-158 \\
\hline & Homo habilis & $\mathrm{OH} 7$ \\
\hline & Homo neanderthalensis & Kebara 2 \\
\hline \multirow[t]{4}{*}{ Lunate } & Proconsul nyanzae & KNM RU $15100^{*}$ \\
\hline & Proconsul heseloni & KNM RU 2036*, C22* \\
\hline & Australopithecus sediba & MH2 UW 88-159 \\
\hline & Homo neanderthalensis & Kebara 2, Amud 1 \\
\hline \multirow[t]{4}{*}{ Triquetrum } & Proconsul nyanzae & KNM RU 15100* \\
\hline & Australopithecus sediba & MH2 UW 88-157 \\
\hline & Au. robustus or early Homo & SKX 3498 \\
\hline & Homo neanderthalensis & Kebara 2, Amud 1 \\
\hline \multirow[t]{10}{*}{ Capitate } & Proconsul africanus & KNM CA 409* \\
\hline & Proconsul heseloni & $\begin{array}{l}\text { KNM RU 2036*, KNM RU } \\
1907^{*}, \text { C25* } \text { C26*, C28* }\end{array}$ \\
\hline & Afropithecus turkanensis & KNM 18365* \\
\hline & Sivapithecus indicus & GSP Y500 17119* \\
\hline & Rudapithecus hungaricus & RUD 167 \\
\hline & cf. Australopithecus & KNM-WT 22944-H** \\
\hline & Australopithecus afarensis & AL 333-40 \\
\hline & Australopithecus africanus & TM 1526 \\
\hline & Australopithescus sediba & MH2 UW 88-105 \\
\hline & Homo neanderthalensis & Kebara 2, Amud 1 \\
\hline \multirow[t]{7}{*}{ Hamate } & Proconsul heseloni & KNM RU 2036* \\
\hline & Sivapithecus paravada & NG Y311940 \\
\hline & Oreopithecus bambolii & Basel 36 \\
\hline & cf. Australopithecus & KNM-WT 22944-I** \\
\hline & Australopithecus afarensis & AL 333-50 \\
\hline & Australopithecus sediba & MH2 UW 88-106 \\
\hline & Homo neanderthalensis & Kebara 2 \\
\hline
\end{tabular}

*Measurements taken from cast.

**Metric data derived from $[65,87]$.

variation in the evolutionary morphology of hominoids suggests that this clade has been subject to increased selective pressures on wrist morphology compared with other primates. Altogether, we find evidence for several instances of independent evolution in wrist bone morphology across haplorrhines, and particularly within hominoids.

The evolutionary morphology of the hamate (Figure 2a, Table 3) sets apart the hylobatids, while the lunate (Figure 2b, Table 3) distinguishes the great apes from other primates. These bones thus seem to reflect instances of autapomorphic morphological evolution. This is particularly true in the hamate, in which only hylobatids display a derived, extremely proximodistally long but dorsopalmarly short hamate. This result is consistent with previous studies $[46,50,51,57]$ and the elongation of other skeletal elements of the hylobatid forelimb, which is considered advantageous for brachiation [58]. Elongation of the hamate is not found, however, in semi-brachiator Ateles, largely because Ateles lacks a distally extended hamulus that is typical of hylobatids $[55,57]$. This lack of convergence may reflect the more varied locomotor repertoire of Ateles, such that they do not engage in the ricochetal brachiation of hylobatids, make use of a prehensile tail during suspensory locomotion, and also engage in a substantial amount (21\% of locomotor time) of quadrupedal walking and running [59]. Previous studies have noted that most of the morphological convergence in the forelimb between Ateles and hylobatids can be found in the shoulder and elbow $[37,60,61]$ and that overall brachiating features are not as pronounced in Ateles [54,60,62].

Conversely, Gorilla, Sivapithecus and, particularly, $A u$. sediba are derived from all of the remaining taxa, evolving in parallel a proximodistally shorter and mediolaterally broader hamate. Au. sediba is further distinguished with an even proximodistally shorter hamate body but comparatively dorsopalmarly tall triquetral facet. This pattern is consistent with increased compressive loading during quadrupedal $[34,63,64]$ and potentially knuckle-walking [33] locomotor behaviours shared between Gorilla and Sivapithecus. Pan does not demonstrate the same morphology as Gorilla, perhaps due to the engagement in more arboreal behaviours (Table 1), but this variation in hamate morphology between Pan and Gorilla has been noted previously $[18,50,65]$. Although previous comparative research on forelimb morphology has concluded that Pan is unique compared with other hominoids and derived from the common Pan-human ancestor [31,66-68], our phylogenetic analysis suggests, when it comes to hamate morphology, that Pan retains a plesiomorphic condition and that Gorilla is derived. Reasons as to why Au. sediba demonstrates such a derived pattern compared with other fossil and extant hominines requires further investigation.

In the lunate (Figure 2b, Table 3), NWMs, OWMs, Hylobates and Miocene apes, have evolved from the ancestral haplorrhine or hominoid condition towards a proximodistally shorter and mediolaterally narrower lunate with a smaller (both proximodistally and mediolaterally) radial facet and a larger (both proximodistally and dorsopalmarly) scaphoid facet. Gorilla generally retains the ancestral hominid condition, while Pan and Pongo have evolved in parallel a slightly dorsopalmarly taller and mediolaterally broader lunate with a larger (both proximodistally and mediolaterally) radial facet but smaller (both proximodistally and dorsopalmarly) scaphoid facet. This shared morphology in Pan with Pongo may 


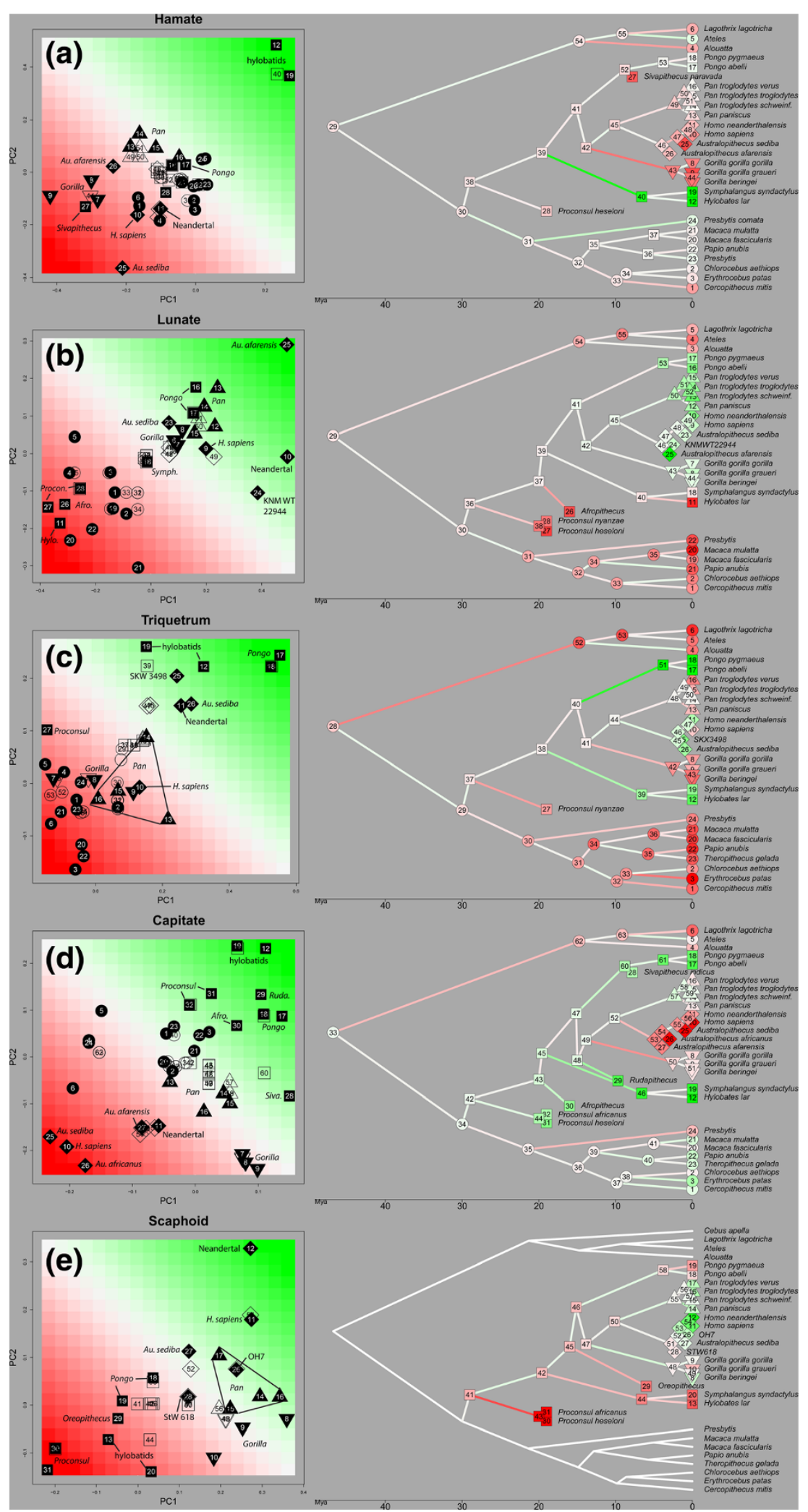

Figure 2 (See legend on next page.) 
(See figure on previous page.)

Figure 2 Results of the phylogenetic principal components analysis (PC1 and PC2) of wrist variables, and the estimated ancestral states (nodes) and rates (branches) plotted in morphospace (left) and on a phylogenetic tree (right) for the (a) hamate, (b) lunate, (c) triquetrum, (d), capitate and (e) scaphoid. Full symbols in the plot represent (observed) tip values in the tree; empty symbols in the plot represent internal nodes (estimated ancestral values) in the tree. In both the plot and tree, circles indicate New World monkeys; squares, hominoid ancestors and extant Asian apes; triangles, Pan; reverse triangles, Gorilla; diamonds, hominins. Colour gradients in the plot are allocated according to the variation of PC scores. Branch colour and hue in the tree indicate direction of change between ancestor and descendant. Figure 2e presenting the scaphoid results shows hominoids only (see Additional file 3 for an additional plot and tree including all haplorrhines).

reflect larger loading of the radiolunate joint in adducted position during climbing $[17,69]$. Although this pattern falls in contrast to previous qualitative and quantitative descriptions of lunate morphology in which the Pongo lunate is noted as being particularly broad and distinguished from that of knuckle-walking African apes [47,54,70], relative to size, Pongo and African apes do not significantly differ in the breadth of the lunate [71].

Interestingly, all fossil hominins, apart from $A u$. sediba, which displays a plesiomorphic hominoid morphology, display derived lunate morphology; $A u$. afarensis, cf., Australopithecus KNM-WT 22944-J and H. neanderthalensis all have a much larger radial facet and smaller scaphoid facet, compared with extant hominoids (including $\mathrm{H}$. sapiens). In Australopithecus, this may reflect continued use of climbing $[17,69]$, although the reasons for its parallel development in $H$. neanderthalensis or its absence in $A u$. sediba require further investigation.

Triquetrum and capitate (Figure 2c,d, Table 3) evolutionary morphology indicates several occurrences of parallel evolution. In both wrist bones, suspensory/brachiating Pongo and hylobatids display parallel evolution from their respective ancestral conditions towards a morphology that is not identical but consistent with greater mobility at the midcarpal joints [72,73]. In the triquetrum, hylobatids and Pongo both demonstrate a short proximodistal length of the lunate facet, while Pongo is further distinguished by dorsopalmarly shorter triquetrum facet but taller hamate facet. In contrast, hominines display various patterns of parallel evolution from the ancestral condition in the opposite direction (dorsopalmarly taller triquetrum but shorter hamate facet, and proximodistally longer lunate facet). These patterns are consistent with the uniquely narrow (and distally-positioned) Pongo triquetrum, compared with the pyramidal morphology and spiral triquetrum-hamate articulation typical of African apes, which are considered related to greater compressive loading and stability $[47,50,57,70]$.

Interestingly, in the triquetrum, the ancestral hominin condition is most similar to the "suspensory/brachiating" morphology, such that all fossil hominins, including $H$. neanderthalensis, are more similar to Asian apes than to $H$. sapiens or African apes [74]. This suggests that the African ape-like triquetrum morphology of $H$. sapiens may have evolved only recently in parallel with Pan and
Gorilla. The pyramidal triquetrum of $H$. sapiens could be related to increased loading on the ulnar side of the wrist and fifth finger during habitual tool-making and tool-use [75], although the loads experienced by the wrist bones during these manipulative behaviours remain to be experimentally tested. This hypothesis is not supported by the habitual, complex tool-use in $H$. neanderthalensis, which retains a primitive triquetrum morphology, although subtle differences in the power and precision grips between $H$. neanderthalensis and $H$. sapiens have been proposed [26,76].

In the capitate (Figure 2d, Table 3), Pan retains the ancestral hominoid condition, while $H$. sapiens and fossil hominins have evolved in parallel with Gorilla a proximodistally shorter length of the capitate body with a mediolaterally broader proximal facet. Therefore, unlike the triquetrum, the similarities in capitate morphology shared between $H$. sapiens and Gorilla evolved earlier, appearing at least by the time of $A u$. afarensis (4 Ma) and being retained in all later hominins. Sivapithecus has also evolved in parallel a capitate morphology that is broadly similar to African apes, as has been previously described [33]. In contrast, extant Pongo and, particularly, hylobatids, demonstrate an extreme version of the ancestral hominoid condition seen in Proconsul and Afropithecus, with a proximodistally longer but dorsopalmarly shorter capitate body and smaller proximal facet (both mediolaterally and dorsopalmarly). Suspensory Rudapithecus also converges on the Pongo condition, which is consistent with previous functional interpretations of its postcranial skeleton [77,78].

Scaphoid evolutionary morphology (Figure 2e, Table 3, Additional file 2) is more complex compared with the other wrist bones. This complexity can be at least partly explained by variation in locomotor behaviours and, perhaps also related to function, by the fusion of the os centrale to the scaphoid in hominines $[16,17,29]$. Asian apes, as well as Oreopithecus, retain the ancestral hominoid condition of a smaller scaphoid body (both proximodistally and mediolaterally), reflecting the absence of scaphoidcentrale fusion, and a larger (both proximodistally and dorsopalmarly) lunate facet, possibly associated with greater mobility among the radial wrist bones [79]. However, Proconsul demonstrates the extreme of this pattern, yet is reconstructed as an arboreal quadruped $[57,58]$. Among hominines, there is parallel evolution each in 
Table 3 Descriptions of the wrist variables, their respective loadings on PC1 and PC2, and the variance explained by each PC

\begin{tabular}{lll}
\hline Carpal & Variable & Description \\
\hline Hamate & LHB-H & $\begin{array}{l}\text { Maximum proximodistal } \\
\text { length of hamate body } \\
\text { (excluding hamulus) }\end{array}$ \\
HHTF & $\begin{array}{l}\text { Maximum dorsopalmar } \\
\text { height of hamate } \\
\text { triquetrum facet }\end{array}$ \\
LHB $\quad \begin{array}{l}\text { Maximum proximodistal length } \\
\text { of hamate body }\end{array}$ \\
LHTF $\quad \begin{array}{l}\text { Maximum proximodistal length } \\
\text { of hamate triquetrum facet }\end{array}$ \\
HHB $\quad \begin{array}{l}\text { Maximum dorsopalmar height } \\
\text { of hamate body (including } \\
\text { hamulus) } \\
\text { HHB-H }\end{array}$ \\
$\begin{array}{l}\text { Maximum dorsopalmar height } \\
\text { of hamate body (excluding } \\
\text { hamulus) } \\
\text { BHB }\end{array} \quad \begin{array}{l}\text { Maximum mediolateral breadth } \\
\text { of hamate body }\end{array}$
\end{tabular}

Variance

explained

$\begin{array}{ll}\text { Lunate } \quad \text { BLRF } & \begin{array}{l}\text { Maximum mediolateral breadth } \\ \text { of lunate radial facet }\end{array} \\ \text { HLRF } & \begin{array}{l}\text { Maximum dorsopalmar height } \\ \text { of lunate radial facet }\end{array} \\ \text { BLB } \quad \begin{array}{l}\text { Maximum mediolateral breadth } \\ \text { of kunate capitate facet }\end{array} & \begin{array}{l}\text { Maximum mediolateral breadth } \\ \text { of lunate body }\end{array} \\ \text { HLTF } \quad \begin{array}{l}\text { Maximum dorsopalmar } \\ \text { height } \\ \text { of lunate triquetrum facet }\end{array} & \begin{array}{l}\text { Maximum dorsopalmar } \\ \text { height of lunate capitate facet }\end{array} \\ \text { HLCF } \quad \begin{array}{l}\text { Maximum proximodistal } \\ \text { length of lunate triquetrum facet }\end{array} \\ \text { HLB } \quad \begin{array}{l}\text { Maximum dorsopalmar height } \\ \text { of lunate body }\end{array} \\ \text { LLB } \quad \begin{array}{l}\text { Maximum proximodistal length } \\ \text { of lunate body }\end{array} \\ \text { HLSF } \quad \begin{array}{l}\text { Maximum dorsopalmar height } \\ \text { of lunate scaphoid facet }\end{array} \\ \text { Maximum proximodistal length } \\ \text { of lunate scaphoid facet }\end{array}$

Variance

explained

Triquetrum HTHF Maximum dorsopalmar height of triquetrum hamate facet

BTHF Maximum mediolateral breadth of triquetrum hamate facet

BTB Maximum mediolateral breadth of triquetrum body

HTLF Maximum dorsopalmar height of triquetrum lunate facet
Table 3 Descriptions of the wrist variables, their respective loadings on $\mathrm{PC1}$ and $\mathrm{PC2}$, and the variance explained by each PC (Continued)

\begin{tabular}{|c|c|c|c|c|}
\hline & LTB & $\begin{array}{l}\text { Maximum proximodistal } \\
\text { length of triquetrum body }\end{array}$ & -0.036 & -0.061 \\
\hline & LTLF & $\begin{array}{l}\text { Maximum proximodistal length } \\
\text { of triquetrum lunate facet }\end{array}$ & -0.08 & -0.972 \\
\hline & HTB & $\begin{array}{l}\text { Maximum dorsopalmar height } \\
\text { of triquetrum body }\end{array}$ & -0.697 & 0.258 \\
\hline $\begin{array}{l}\text { Variance } \\
\text { explained }\end{array}$ & & & $72.75 \%$ & $12.96 \%$ \\
\hline \multirow[t]{6}{*}{ Capitate } & $\mathrm{BCN}$ & $\begin{array}{l}\text { Minimum mediolateral breadth } \\
\text { of capitate neck }\end{array}$ & 0.987 & -0.121 \\
\hline & $\mathrm{BCB}$ & $\begin{array}{l}\text { Maximum mediolateral breadth } \\
\text { of capitate body }\end{array}$ & 0.165 & 0.367 \\
\hline & $\mathrm{BCPF}$ & $\begin{array}{l}\text { Maximum mediolateral breadth } \\
\text { of capitate proximal facet }\end{array}$ & 0.035 & -0.834 \\
\hline & LCB & $\begin{array}{l}\text { Maximum proximodistal length } \\
\text { of capitate body }\end{array}$ & -0.096 & 0.972 \\
\hline & HCPF & $\begin{array}{l}\text { Maximum dorsopalmar height } \\
\text { of capitate proximal facet }\end{array}$ & -0.859 & -0.107 \\
\hline & $\mathrm{HCB}$ & $\begin{array}{l}\text { Maximum dorsopalmar height } \\
\text { of capitate body }\end{array}$ & -0.971 & 0.087 \\
\hline $\begin{array}{l}\text { Variance } \\
\text { explained }\end{array}$ & & & $70.93 \%$ & $22.14 \%$ \\
\hline \multirow[t]{7}{*}{ Scaphoid* } & LSB & $\begin{array}{l}\text { Maximum proximodistal length } \\
\text { of scaphoid body }\end{array}$ & 0.951 & -0.089 \\
\hline & HSB & $\begin{array}{l}\text { Maximum dorsopalmar height } \\
\text { of scaphoid body }\end{array}$ & 0.352 & -0.075 \\
\hline & LSRF & $\begin{array}{l}\text { Maximum proximodistal length } \\
\text { of scaphoid radial facet }\end{array}$ & 0.243 & 0.146 \\
\hline & HSRF & $\begin{array}{l}\text { Maximum dorsopalmar height } \\
\text { of the scaphoid radial facet }\end{array}$ & 0.186 & -0.13 \\
\hline & BSB & $\begin{array}{l}\text { Maximum mediolateral breadth } \\
\text { of scaphoid body }\end{array}$ & -0.045 & 0.936 \\
\hline & HSLF & $\begin{array}{l}\text { Maximum dorsopalmar height } \\
\text { of scaphoid lunate facet }\end{array}$ & -0.056 & -0.36 \\
\hline & LSLF & $\begin{array}{l}\text { Maximum proximodistal length } \\
\text { of scaphoid lunate facet }\end{array}$ & -0.693 & -0.129 \\
\hline $\begin{array}{l}\text { Variance } \\
\text { explained }\end{array}$ & & & $65.12 \%$ & $16.32 \%$ \\
\hline
\end{tabular}

Variables with the highest positive and negative loadings are highlighted in bold. *Note that the os centrale is fused to the scaphoid in Pan, Gorilla, humans and fossil hominins and thus measurements such as the maximum height of the scaphoid body (HSB) and height of the scaphoid's lunate facet (HSLF) are not necessarily developmentally or morphologically homologous across our primate sample (i.e., the fused os centrale is included in the measurement for these taxa, but not for the other primates in the sample).

$53.99 \% \quad 22.61 \%$

$\mathbf{0 . 9 0 7} 0.219$

Gorilla, Pan, and fossil hominins (H. sapiens, $H$. neanderthalensis, $\mathrm{OH} 7$ and $A u$. sediba) towards a smaller lunate articulation and a larger scaphoid body. Although the latter reflects fusion of the os centrale to the scaphoid body, this does not imply that scaphoid-centrale fusion occurred in parallel since other fossil hominins also have a fused os centrale and yet comparatively smaller scaphoid bodies. Australopithecus sp. StW 618 retains a morphology that is more 
similar to the ancestral hominoid condition than the more Pan-like morphology of $H$. habilis and (to a lesser extent) $A u$. sediba. The $H$. sapiens scaphoid morphology shares morphological similarities with both $A u$. sediba and $H$. habilis and thus it remains unclear which may better represent the ancestral condition for later Homo. Altogether, this analysis demonstrates substantial parallel evolution in scaphoid morphology across hominines.

\section{Conclusions}

Analysis of hominoid wrist morphology within a broad, phylogenetic context confirms numerous instances of parallel evolution across haplorrhines and among extant hominoids that have been recognised by previous studies [8,50,54], including shared morphology between Pongo and hylobatids [8,57], Pongo and Rudapithecus [77,78], and Sivapithecus and African apes [33,63,64]. However, this analysis also reveals substantial parallel evolution within extant and fossil hominines, some of which has been previously discussed $[18,20,30]$ but not demonstrated within a robust phylogenetic analysis. There is no consistent pattern of evolutionary change within taxa across all five wrist bones. Instead, results indicate that extant and fossil variation in wrist morphology is best explained by a mixture of parallel and synapomorphic changes across different wrist bones, each potentially influenced by both function (i.e., corresponding to similar locomotor behaviours) and phylogeny.

The occurrence of different processes of evolution in combination with a higher variation in wrist bone morphology in hominoids [53-56,80] indicates an increased selective pressure and a higher evolvability of hominoid wrist bone morphology in comparison with other primates. This result is to some degree not surprising given the large range of variation in body size and locomotor behaviours that typify the hominoid clade (Table 1). In addition, within the context of hominoid fossil record, extreme suspensory behaviour has likely evolved multiple times in hylobatids, Pongo, Oreopithecus and potentially Rudapithecus $[8,61]$ allowing for both the development of similar and different morphological features to meet similar same functional demands. In contrast, individual hominoid taxa all retain some aspect of primitive ancestral morphology in some wrist bones, while being derived in others. Recent work $[31,67,68]$ has suggested that extant African apes, and particularly Pan, are too derived to provide informative morphological comparisons when interpreting hominin morphology. Our results suggest that while this may be true for the scaphoid and triquetrum morphology, African apes retain ancestral morphologies in the other wrist bones and thus should not be discounted within an evolutionary context. These results highlight the importance of incorporating a broad comparative sample of species, phylogenetic information and time within morphological studies and put into context the use of particular extant species for morphological comparisons when interpreting hominin morphology.

Much debate remains over the locomotor behaviour of the pre-bipedal common ancestor of Homo and Pan $[8,17,18,20,29,81]$, in which the shared morphology of the wrist has played a central role [16-19]. One model envisions the pre-bipedal ancestor as a knuckle-walker that had already come down to the ground, similar to the locomotor behavior used by African apes [17,29,81,82]. In the alternative model, early human bipedalism is seen as having evolved from a more generalized arboreal, climbing-oriented ancestor, a mode of locomotion that is used by all living apes [18,23,83-85]. Each scenario has important and profoundly different implications for understanding the evolution of ape and human locomotion. The phylogenetically-integrated approach applied here offers new insight into this debate; We reveal a substantial amount of parallel evolution in wrist morphology among extant Pan, Gorilla and H. sapiens, as well as fossil hominins, including in the morphologies of the scaphoid, triquetrum and capitate that are typically considered advantageous for accommodating increased compressive loading during knuckle-walking $[17,47,50]$. These results may add further support to hypotheses that both knucklewalking behavior $[18,20]$ and the African ape-like features of hominins [27] have evolved in parallel within hominines. However, this signal is not consistent across all wrist bones included in this study and the functional association between these features and knuckle-walking locomotion requires further testing, especially given the variation in wrist and hand morphology across African apes $[18,86]$. Further phylogenetically-integrated analyses of other skeletal elements within the forelimb are also needed to robustly test these hypotheses.

In conclusion, we demonstrate how a combination of parallel and synapomorphic evolution across different wrist bones best explains the morphological diversity observed in extant and fossil hominoids. These results exemplify how the evolution of a single skeletal anatomical unit - the wrist - can be shaped by a diverse pattern of evolutionary trends, with each bone having a degree of functional and/or evolutionary independence. The diversity in evolutionary patterns across the wrist bones revealed here contributes to explaining the mosaic nature of the wrist and other postcranial morphology observed in recent fossil finds $[3,4,87,88]$.

\section{Methods}

\section{Sample}

Morphometric data were collected from adult individuals of a diverse sample of haplorrhines of varying body size and locomotor behaviours (Table 1). All individuals were free of obvious pathologies and considered adult 
based on dental eruption and/or epiphyseal fusion throughout the associated skeleton. Fossil specimens include Miocene hominoids and Plio-Pleistocene hominins (Table 2). Miocene hominoid genera include early Miocene Proconsul (20-17 Ma) and Afropithecus (17.5-17 Ma), midto late Miocene Sivapithecus (12.5-8.5 Ma), and late Miocene Rudapithecus (10 Ma) and Oreopithecus (9$7 \mathrm{Ma})[8,89]$. The postcranial skeletons of Proconsul heseloni and P. nyanzae are well-represented and the locomotor behaviour of both has been reconstructed generally as pronograde, above-branch, arboreal quadrupedalism using a grasping, palmigrade hand posture $[8,90,91]$. Morphological similarities between the few postcranial remains of Afropithecus and P. nyanzae, suggest that the former was also an arboreal quadruped [92]. Sivapithecus postcranial remains reveal a suite of features that are unlike any extant primate analogue $[34,63,64,93,94]$. Generally it is considered to have been mainly arboreal, emphasizing pronograde, arboreal quadrupedalism $[63,64,93,95]$, but more recent research has proposed that vertical climbing [34] and perhaps knucklewalking [33] were part of the Sivapithecus locomotor repertoire. Rudapithecus postcranial remains demonstrate distinct similarities to extant great apes [77], including strong phalangeal curvature [78], all of which emphasize suspensory locomotion. The Oreopithecus postcranium is unique, with several morphological features suggesting highly specialized orthograde behaviors, including suspension [96,97] and perhaps bipedalism [98], while some have suggested its hand was capable of hominin-like grasping dexterity [99], but see [100].

Table 3 lists the measurements for each bone, which are depicted graphically in the supplementary material (Additional file 3). Mean and standard deviation for each variable, wrist bone and each taxon are given in Additional file 1 . These metrics were chosen to quantify the overall size of each wrist bone and their articular facets in a manner that could be reliably measured in a diverse sample of morphologies across different primates. All measurements were taken by one observer (T.L.K.) and on the right side, unless unavailable (then measurements were taken on the left). Intraobserver measurement error was tested on $\mathrm{n}=25$ specimens on three separate occasions. Measurement errors were calculated using methods outlined by White [101], and the average error was less than $1 \%$ for most variables, although closer to $1.5 \%$ for measurement of the length of the scaphoid body (LSB), length and breadth of lunate's radial facet. This measurement error is consistent with other morphometric studies of the hand [102]. Measurements for all Miocene hominoid taxa were taken on casts, except for Sivapithecus parvada (NG Y311 940) and Rudapithecus (RUD 167). Measurements for all Plio-Pleistocene hominin specimens were taken on the original fossils, except those of cf.
Australopithecus KNM WT 22944, which were taken from casts (Table 2).

Since body weight information is most often not available with museum specimens, all of the raw measurements for each carpal bone were used to create a geometric mean. The geometric mean was used a sizecorrecting variable [103-105].

\section{Phylogeny}

The primate molecular phylogeny was taken from the $10 \mathrm{k}$ Trees Project (version 3) [106]. Divergence dates for great apes were amended following [107]. Fossil species were placed onto the phylogeny following the best solution given the divergence dates of the molecular phylogeny [106] and the inferred taxonomic divergence and time of last occurrence of the fossils following recently published information $[3,78,108]$.

\section{Statistical procedure}

Size-corrected morphological measurements were used as input to a phylogenetically weighted principal components analysis in order to minimize type I error in statistical estimators $[109,110]$. Output scores represent species values that are weighted for phylogenetic distance. The variation of PC scores (for both observed and inferred ancestral species) between hominoids and other haplorrhines for each $\mathrm{PC}$ for each bone were compared using an F-test for equality of variance.

\section{Inferring variable rates and ancestral estimates}

The output scores of the phylogenetically-weighted principal components analyses were used to estimate rates of change and ancestral values. Phylogenetic comparative methods infer evolutionary trends based on variation of a trait across different species and a phylogenetic tree that describes the relatedness between those species [111]. To infer changes on ancestral branches, models of evolution are used that lay out the principles to 'count back in time' [11,112]. We use a method ('Independent Evolution', 'IE') that is based on the principles of an Adaptive Peak model of evolution [112] and allows ancestral state and variable rate estimation for individual branches of a phylogenetic tree [12,45]. This method incorporates aspects of more traditionally used models (Brownian Motion and Ornstein-Uhlenbeck) as special cases. The assumptions of the IE method consider that extant variation is the necessary result of foregone changes, and thus that extant trait variation bears crucial information on evolutionary history. IE infers evolution based only on observed (extant and/or fossil) variation and phylogenetic relatedness (no a priori model parameters), and therefore has less stringent data assumptions and a decreased reliance on a prior model assumptions [113]. 


\section{Phylogenetic mapping}

To visualize the temporal origin and rate of underlying morphological changes for all individual branches of the phylogenetic tree, we mapped the inferred rates and ancestral values back onto the phylogeny in a colour-coded manner. Plots in Figure 2 indicate the PCA-scores for all observed (full symbols) and estimated ancestral values (empty symbols). Colour codes (shades of green and red) were chosen to indicate a gradual differentiation between PC1 and PC2. Corresponding colour codes were used to represent the observed and estimated values in the tree. The colour hue for the nodal values hereby represents their location in PC1-PC2 morphospace. Colour codes for the branches in the tree relate to the rate of change in either direction of the morphospace (green or red-coded in the plot). The colour hue for the branches in the tree corresponds to the absolute value of the rate of change (with a more intense colour for higher rates of change).

\section{Additional files}

Additional file 1: Mean (above) and standard deviation (below) for each carpal variable and the geometric mean (geomean) in each taxon for the (a) hamate, (b) lunate, (c) triquetrum, (d) capitate and (e) scaphoid. Variable acronyms the same as in Table 1.

Additional file 2: Measurements for each wrist bone used in this analysis, shown on human bones as an example. Acronyms are the same as described in Table 3.

Additional file 3: Results of the phylogenetic principal component analysis (PC1 and PC2) on the scaphoid wrist variables, including all haplorrhine taxa, and the estimated ancestral states (nodes) and rates (branches) plotted in morphospace (left) and on a

phylogenetic tree (right). Symbols and colour gradient the same as described in Figure 2.

\section{Competing interests}

The authors declare that they have no competing interests.

\section{Authors' contributions}

All authors participated in conceiving and designing the study. TLK provided data. JBS performed the statistical analyses. All authors wrote the paper. All authors read and approved the final manuscript.

\section{Acknowledgements}

This research was funded by the Natural Sciences and Engineering Research Council (NSERC) of Canada, the General Motors Women in Science and Mathematics Award and the Max Planck Society (TLK), the Fundação para a Ciência e a Tecnologia [grant number SFRH/BD/60349/ 2009] (APB), and the UK Natural Environment Research Council [grant number NE/H022937/1] (JBS).

We thank Christophe Soligo and two anonymous reviewers for their useful comments and insights. We are grateful to F. Spoor and $L$ Kordos for access to fossils under their care, D. Begun, A. Walker and M. Rose for access to Miocene fossil casts, and the following institutions and curators for access to extant and fossil specimens under their care: W. Wendelen, M. Louette and E. Gilissen (Musée royal del'Afrique centrale); M. Harman (PowellCotton Museum); L. Gordon and D. Hunt (Smithsonian Institution); Y. HaileSelassie and L. Jellema (Cleveland Museum of Natural History); J. Chupasko and M. Omura (Harvard Museum of Comparative Zoology); J. Sirianni and E. Hammerl (SUNY University at Buffalo); J. Eger and S. Woodward (Royal Ontario Museum); F. Burton (University of Toronto); F. Mayer (Berlin Museum für Naturkunde), V. Volpato (Frankfurt Senckenberg Museum), C. Boesch (Max Planck Institute for Evolutionary Anthropology), M. Teschler-
Nicola and R. Muehl (Vienna Natural History Museum); Y. Rak and I. Hershkovitz (Tel Aviv University); W. Kimbel, G. Semishaw and G. Shimelies (National Museum of Ethiopia); A. Kweka and A. Gidna (Tanzanian National Museum and House of Culture). B. Zipfel and R. Clarke (University of the Witwatersrand); S. Potze (Ditsong National Museum of Natural History).

\section{Author details}

${ }^{1}$ School of Anthropology and Conservation, University of Kent, Canterbury, UK. ²Department of Human Evolution, Max Planck Institute for Evolutionary Anthropology, Leipzig, Germany. ${ }^{3}$ Department of Anthropology, University College London, London, UK. ${ }^{4}$ Department of Anthropology, Stony Brook University, Stony Brook, USA. ${ }^{5}$ Department of Genetics, Evolution and Environment, University College London, London, UK.

Received: 13 May 2013 Accepted: 11 October 2013

Published: 23 October 2013

\section{References}

1. Rudwick MJS: The inference of function from structure in fossils. Br J Philos Sci 1964, 15(57):27-40.

2. Carrano MT: Homoplasy and the evolution of dinosaur locomotion. Paleobiology 2000, 26(3):489-512.

3. Kivell TL, Kibii JM, Churchill SE, Schmid P, Berger LR: Australopithecus sediba hand demonstrates mosaic evolution of locomotor and manipulative abilities. Science 2011, 333(6048):1411-1417.

4. Ward CV: Interpreting the posture and locomotion of australopithecus afarensis: where do we stand? In Yearbook of physical anthropology, Vol 45. Edited by Ruff C.; 2002:185-215. vol. 45.

5. Carroll RL: Patterns and processes of vertebrate evolution, vol. 2. Cambridge: Cambridge University Press; 1997.

6. Hallgrímsson B, Hall BK: Variation: a central concept in biology. Burlington: Academic Press; 2011.

7. Kemp TS: The origin and evolution of mammals. Oxford: Oxford University Press; 2005.

8. Begun DR: How to identify (as opposed to define) a homoplasy: examples from fossil and living great apes. J Hum Evol 2007, 52(5):559-572.

9. Martin RD, Martin A-E: Primate origins and evolution: a phylogenetic reconstruction. Princeton: Princeton University Press; 1990.

10. Brooks DR, McLennan DA: The nature of diversity: an evolutionary voyage of discovery. Chicago: University of Chicago Press; 2002.

11. Pagel M: Inferring the historical patterns of biological evolution. Nature 1999, 401(6756):877-884.

12. Smaers JB, Dechmann DKN, Goswami A, Soligo C, Safi K: Comparative analyses of evolutionary rates reveal different pathways to encephalization in bats, carnivorans, and primates. Proc Natl Acad Sci U S A 2012, 109(44):18006-18011.

13. Sakamoto $M$, Ruta $M$ : Convergence and divergence in the evolution of cat skulls: temporal and spatial patterns of morphological diversity. PLoS One 2012, 7(7):e39752.

14. Demes B, Larson SG, Stern JT, Jungers WL, Biknevicius AR, Schmitt D: The kinetics of primate quadrupedalism: hindlimb drive reconsidered. J Hum Evol 1994, 26(5-6):353-374.

15. Schmitt $D$ : Insights into the evolution of human bipedalism from experimental studies of humans and other primates. J Exp Biol 2003 206(9):1437-1448.

16. Marzke MW: Origin of the human hand. Am J Phys Anthropol 1971, 34(1):61-84.

17. Richmond BG, Begun DR, Strait DS: Origin of human bipedalism: the knuckle-walking hypothesis revisited. Am J Phys Anthropol 2001, 116(S33):70-105.

18. Kivell TL, Schmitt D: Independent evolution of knuckle-walking in african apes shows that humans did not evolve from a knuckle-walking ancestor. Proc Natl Acad Sci U S A 2009, 106(34):14241-14246.

19. Tuttle RH: Knuckle-walking and problem of human origins. Science 1969 166(3908):953-961

20. Dainton M, Macho GA: Did knuckle walking evolve twice? J Hum Evol 1999, 36(2):171-194.

21. Stern JT, Susman RL: The locomotor anatomy of australopithecus afarensis. Am J Phys Anthropol 1983, 60(3):279-317. 
22. Marzke MW: Joint functions and grips of the australopithecus afarensis hand, with special reference to the region of the capitate. $J$ Hum Evol 1983, 12(2):197-211.

23. Stern J: Before bipedality. Yrbk Phys Anthropol 1975, 19:59-68.

24. Panger MA, Brooks AS, Richmond BG, Wood B: Older than the oldowan? rethinking the emergence of hominin tool use. Evol Anthropol 2002, 11(6):235-245.

25. Tocheri MW: Three-dimensional riddles of the radial wrist: derived carpal and carpometacarpal joint morphology in the genus homo and the implications for understanding the evolution of stone tool-related behaviors in hominins. Tempe: Arizona State University; 2007

26. Niewoehner WA, Weaver AH, Trinkaus E: Neandertal capitate metacarpal articular morphology. Am J Phys Anthropol 1997, 103(2):219-233.

27. Napier J: Fossil hand bones from olduvai gorge. Nature 1962, 196(4853):409-411.

28. Begun DR: Relations among the great apes and humans: New interpretations based on the fossil great ape dryopithecus. Yearb Phys Anthropol 1994, 37:11-63.

29. Begun DR: Miocene fossil hominids and the chimp-human clade. Science 1992, 257(5078):1929.

30. Dainton M: Palaeoanthropology - Did our ancestors knuckle-walk? Nature 2001, 410(6826):324-325.

31. Lovejoy CO, Suwa G, Simpson SW, Matternes JH, White TD: The great divides: ardipithecus ramidus reveals the postcrania of Our last common ancestors with african apes. Science 2009, 326(5949):100-106.

32. De Beer GR: Embryos and ancestors, revised edition edn. Oxford: Oxford University Press; 1954.

33. Begun DR, Kivell TL: Knuckle-walking in sivapithecus? the combined effects of homology and homoplasy with possible implications for pongine dispersals. J Hum Evol 2011, 60(2):158-170.

34. Madar SI, Rose MD, Kelley J, MacLatchy L, Pilbeam D: New Sivapithecus postcranial specimens from the Siwaliks of Pakistan. J Hum Evol 2002, 42(6):705-752.

35. Berger LR, De Ruiter DJ, Churchill SE, Schmid P, Carlson KJ, Dirks PH, Kibi JM: Australopithecus sediba: A new species of Homo-like australopith from South Africa. Science 2010, 328(5975):195-204.

36. Berger LR: The mosaic nature of Australopithecus sediba. Science (New York, NY) 2013, 340(6129):163-165.

37. Young NM: A reassessment of living hominoid postcranial variability: implications for ape evolution. J Hum Evol 2003, 45(6):441-464.

38. Lockwood CA, Fleagle JG: The recognition and evaluation of homoplasy in primate and human evolution. Am J Phys Anthropol 1999, 110(S29):189-232.

39. Lockwood CA: Homoplasy and adaptation in the atelid postcranium. Am J Phys Anthropol 1999, 108(4):459-482

40. Sarmiento EE, Stiner E, Mowbray K: Morphology-based systematics (MBS) and problems with fossil hominoid and hominid systematics. Anat Rec 2002, 269(1):50-66.

41. Lockwood CA: Adaptation and functional integration in primate phylogenetics. J Hum Evol 2007, 52(5):490-503.

42. Williams BA: Comparing levels of homoplasy in the primate skeleton. J Hum Evol 2007, 52(5):480-489.

43. Collard M, Wood B: Hominin homoiology: an assessment of the impact of phenotypic plasticity on phylogenetic analyses of humans and their fossil relatives. J Hum Evol 2007, 52(5):573-584.

44. Diogo R, Wood B: Soft-tissue anatomy of the primates: phylogenetic analyses based on the muscles of the head, neck, pectoral region and upper limb, with notes on the evolution of these muscles. J Anat 2011, 219(3):273-359.

45. Smaers JB, Vinicius L: Inferring macro-evolutionary patterns using an adaptive peak model of evolution. Evol Ecol Res 2009, 11(7):991-1015.

46. Jenkins F: Wrist rotation in primates: a critical adaptation for brachiators Symp Zool Soc Lond: 1981 1981, 1981:429-451.

47. Jenkins F, Fleagle J: Knuckle-walking and the functional anatomy of the wrists in living apes. In Primate functional morphology and evolution. Edited by Tuttle R. The Hague: Mouton \& Co; 1975:213-227.

48. Ziemer LK: Functional morphology of forelimb joints in the woolly monkey lagothrix lagothricha. Contrib Primatol 1978, 14:1-130.

49. Hamrick MW: Functional morphology of the lemuriform wrist joints and the relationship between wrist morphology and positional behavior in arboreal primates. Am J Phys Anthropol 1996, 99(2):319-344.

50. Richmond BG: Functional morphology of the midcarpal joint in knucklewalkers and terrestrial quadrupeds. In Human origins and environmental backgrounds. Chicago: Springer; 2006:105-122.
51. Kivell TL: Ontogeny of the hominoid midcarpal joint and implications for the origin of human bipedalism. Toronto: University of Toronto; 2007.

52. Daver G, Berillon G, Grimaud-Herve D: Carpal kinematics in quadrupedal monkeys: towards a better understanding of wrist morphology and function. J Anat 2012, 220(1):42-56.

53. Lewis OJ: Osteological features characterizing wrists of monkeys and apes, with a reconsideration of this region in dryopithecus-(proconsul)africanus. Am J Phys Anthropol 1972, 36(1):45-58.

54. Corruccini RS: Comparative osteometrics of the hominoid wrist joint, with special reference to knuckle-walking. J Hum Evol 1978, 7(4):307-321.

55. Corruccini RS, Ciochon RL, McHenry HM: Osteometric shape relationships in wrist joint of some anthropoids. Folia Primatol 1975, 24(4):250-274.

56. O'connor BL: Functional morphology of cercopithecoid wrist and inferior radioulnar joints, and their bearing on some problems in evolution of hominoidea. Am J Phys Anthropol 1975, 43(1):113-121.

57. Lewis OJ: Functional morphology of the evolving hand and foot. Oxford: Clarendon Press; 1989.

58. Drapeau MS, Ward CV: Forelimb segment length proportions in extant hominoids and australopithecus afarensis. Am J Phys Anthropol 2006, 132(3):327-343.

59. Cant JGH, Youlatos D, Rose MD: Locomotor behavior of lagothrix lagothricha and ateles belzebuth in yasuni national park, ecuador: general patterns and nonsuspensory modes. J Hum Evol 2001, 41(2):141-166

60. Rose MD: Functional morphological similarities in the locomotor skeleton of miocene catarrhines and platyrrhine monkeys. Folia Primatol 1996, 66(1-4):7-14.

61. Larson SG: Parallel evolution in the hominoid trunk and forelimb. Evol Anthropol: Issues, News, and Rev 1998, 6(3):87-99.

62. Youlatos D: Atelines, apes and wrist joints. Folia Primatol 1996, 67(4):193-198.

63. Rose M: Hominoid postcranial specimens from the middle miocene chinji formation, pakistan. J Hum Evol 1984, 13(6):503-516.

64. Spoor CF, Sondaar PY, Hussain ST: A new hominoid hamate and first metacarpal from the late miocene nagri formation of pakistan. J Hum Evol 1991, 21(6):413-424.

65. Ward CV, Leakey MG, Brown B, Brown F, Harris J, Walker A: South turkwel: a new pliocene hominid site in kenya. J Hum Evol 1999, 36(1):69-95.

66. Drapeau MSM, Ward CV: Forelimb segment length proportions in extant hominoids and australopithecus afarensis. Am J Phys Anthropol 2007, 132(3):327-343.

67. Sayers K, Raghanti MA, Lovejoy CO: Human evolution and the chimpanzee referential doctrine. Annu Rev Anthropol 2012, 41:1.

68. Sayers K, Lovejoy CO: The chimpanzee has no clothes. Curr Anthropol 2008, 49(1):87-114

69. Heinrich $R$, Rose $M$, Leakey RE, Walker A: Hominid radius from the middle pliocene of lake turkana, Kenya. Am J Phys Anthropol 1993, 92(2):139-148.

70. Sarmiento EE: Anatomy of the hominoid wrist joint: its evolutionary and functional implications. Int J Primatol 1988, 9(4):281-345.

71. Zylstra M: Functional morphology of the hominoid forelimb: implications for knuckle-walking and the origin of hominid bipedalism. Toronto: University of Toronto; 1999.

72. Orr CM, Leventhal EL, Chivers SF, Marzke MW, Wolfe SW, Crisco JJ: Studying Primate Carpal Kinematics in Three Dimensions Using a ComputedTomography-Based Markerless Registration Method. Anat Rec-Adv Integr Anat Evol Biol 2010, 293(4):692-709.

73. Rose M: Functional anatomy of the Cheiridia. In Orang-utan biology. Edited by Schwartz J. Oxford: Oxford University Press; 1988:299-310.

74. Kivell TL: A comparative analysis of the hominin triquetrum (SKX 3498) from Swartkrans, South Africa. S Afr J Sci 2011, 107(5-6):60-69.

75. Marzke MW, Toth N, Schick K, Reece S, Steinberg B, Hunt K, Linscheid R, An K: EMG study of hand muscle recruitment during hard hammer percussion manufacture of oldowan tools. Am J Phys Anthropol 1998, 105(3):315-332.

76. Maki J, Trinkaus E: Opponens pollicis mechanical effectiveness in neandertals and early modern humans. Paleo Anthropol 2011, 2011:62-71.

77. Kivell TL, Begun DR: New primate carpal bones from Rudabánya (late Miocene, Hungary): taxonomic and functional implications. J Hum Evol 2009, 57(6):697-709.

78. Begun DR, Nargolwalla MC, Kordos L: European Miocene hominids and the origin of the African ape and human clade. Evol Anthropol: Issues, News, and Rev 2012, 21(1):10-23.

79. Tuttle RH: Quantitative and functional studies on hands of anthropoidea. I. The hominoidea. J Morphol 1969, 128(3):309-363. 
80. McHenry $\mathrm{H}$, Corruccini R: The wrist of proconsul africanus and the origin of hominoid postcranial adaptations. In New interpretations of Ape and human ancestry. New York: Plenum Press; 1983:353-367.

81. Richmond BG, Strait DS: Evidence that humans evolved from a knucklewalking ancestor. Nature 2000, 404(6776):382-385.

82. Gebo DL: Climbing, brachiation, and terrestrial quadrupedalism: historical precursors of hominid bipedalism. Am J Phys Anthropol 1996, 101(1):55-92.

83. Rose M: The process of bipedalization in hominids. In Origine (s) de la bipédie chez les hominidés. Edited by Coppens Y, Senut B. Paris: CNRS; 1991:37-48.

84. Crompton RH, Pataky TC, Savage R, D'Août K, Bennett MR, Day MH, Bates K Morse S, Sellers WI: Human-like external function of the foot, and fully upright gait, confirmed in the 3.66 Million year old laetoli hominin footprints by topographic statistics, experimental footprint-formation and computer simulation. J The Royal Society Interface 2012, 9(69):707-719.

85. Thorpe SKS, Crompton RH: Orangutan positional behavior and the nature of arboreal locomotion in hominoidea. Am J Phys Anthropol 2006, 131(3):384-401.

86. Inouye $S$, Shea B: The implications of variation in knuckle-walking features for models of african hominoid locomotor evolution. $J$ Anthropol Sci 2004, 82:67-88.

87. Ward CV, Kimbel WH, Harmon EH, Johanson DC: New postcranial fossils of australopithecus afarensis from hadar, ethiopia (1990-2007). J Hum Evol 2012, 63(1):1-51.

88. Orr CM, Tocheri MW, Burnett SE, Awe RD, Saptomo EW, Sutikna T, Jatmiko, Wasisto S, Morwood MJ, Jungers WL: New wrist bones of homo floresiensis from liang Bua (flores, indonesia). J Hum Evol 2013, 64(2):109-129.

89. Harrison T: Dendropithecoidea, proconsuloidea, and hominoidea. In Cenozoic mammals of africa edited by werdelin L, sanders W. Berkeley: University of California Press; 2010:429-469.

90. Begun DR, Teaford MF, Walker A: Comparative and functional anatomy of proconsul phalanges from the kaswanga primate site, rusinga island, kenya. J Hum Evol 1994, 26:89-165.

91. Ward CV: Afropithecus, proconsul, and the primitive hominoid skeleton. In Primate locomotion: recent advances New york: plenum. Edited by Strasser E. New York: Plenum; 1998:337-352.

92. Leakey R, Leakey MG, Walker A: Morphology of afropithecus turkanensis from kenya. Am J Phys Anthropol 1988, 76(3):289-307.

93. Rose M: Further hominoid postcranial specimens from the Late Miocene Nagri Formation of Pakistan. J Hum Evol 1986, 15(5):333-367.

94. DeSilva JM, Morgan ME, Barry JC, Pilbeam D: A hominoid distal tibia from the miocene of pakistan. J Hum Evol 2010, 58(2):147-154.

95. Richmond $\mathrm{BG}$, Whalen M: Forelimb function, bone curvature and phylogeny of sivapithecus. In Eurasian neogene hominoid phylogeny. Edited by de Bonis L, Koufos G. Cambridge: Camrbidge University Press; 2001:326-348.

96. Harrison T: The implications of oreopithecus bambolii for the origins of bipedalism. In Origine (s) de la bipédie chez les hominidés. Edited by Coppens Y, Senut B. Paris: CNRS; 1991:235-244.

97. Straus WL: Primate taxonomy and Oreopithecus. Science 1961, 133(345):760-761.

98. Rook L, Bondioli L, Köhler M, Moyà-Solà S, Macchiarelli R: Oreopithecus was a bipedal ape after all: evidence from the iliac cancellous architecture. Proc Natl Acad Sci 1999, 96(15):8795-8799.

99. Moyà-Solà $S$, Köhler M, Rook L: Evidence of hominid-like precision grip capability in the hand of the Miocene ape Oreopithecus. Proc Natl Acad Sci 1999, 96(1):313-317.

100. Susman RL: Oreopithecus bambolii: an unlikely case of hominidlike grip capability in a miocene ape. J Hum Evol 2004, 46(1):105-117.

101. White TD: Human osteology. San Diego: Academic Press; 2000

102. Weinberg SM, Scott NM, Neiswanger K, Marazita ML: Intraobserver error associated with measurements of the hand. Am J Hum Biol 2005, 17(3):368-371.

103. Jungers WL, Falsetti $A B$, Wall $C$ : Shape, relative size, and size-adjustments in morphometrics. Yearb Phys Anthropol, 1995 1995, 38:137-161.

104. Mosimann JE: Size allometry: Size and shape variables with characterizations of lognormal and generalized gamma distributions. J Am Stat Assoc 1970, 65(330):930-945.

105. Mosimann JE, James FC: New statistical methods for allometry with application to florida red-winged blackbirds. Evolution 1979, 33(1):444-459.

106. Arnold C, Matthews LJ, Nunn CL: The 10 k trees website: a New online resource for primate phylogeny. Evol Anthropol 2010, 19(3):114-118.

107. Langergraber KE, Prüfer K, Rowney C, Boesch C, Crockford C, Fawcett K, Inoue E, Inoue-Muruyama M: Mitani JC. Generation times in wild chimpanzees and gorillas suggest earlier divergence times in great ape and human evolution. Proceedings of the National Academy of Sciences: Muller MN; 2012.

108. Begun DR, Ward CV, Rose MD: Events in hominoid evolution. In Function, phylogeny and fossils: Miocene hominoid evolution and adaptation. Edited by Begun DR, Ward CV, Rose MD. New York: Plenum; 1997:389-415.

109. Revell L: Size-correction and principal components for interspecific comparative studies. Evolution 2009, 63(12):3258-3268.

110. Revell $\amalg$ : phytools: an R package for phylogenetic comparative biology (and other things). Methods Ecol Evol 2012, 3(2):217-223.

111. Harvey PH, Pagel M: The comparative method in evolutionary biology. New York: Oxford University Press; 1991.

112. Felsenstein J: Phylogenies and quantitative characters. Annu Rev Ecol Syst 1988, 19:445-471.

113. Akaike $\mathrm{H}$ : A new look at the statistical model identification. IEEE Trans Autom Control 1974, 19(6):716-723.

doi:10.1186/1471-2148-13-229

Cite this article as: Kivell et al: Different evolutionary pathways underlie the morphology of wrist bones in hominoids. BMC Evolutionary Biology 2013 13:229.

\section{Submit your next manuscript to BioMed Central and take full advantage of:}

- Convenient online submission

- Thorough peer review

- No space constraints or color figure charges

- Immediate publication on acceptance

- Inclusion in PubMed, CAS, Scopus and Google Scholar

- Research which is freely available for redistribution 